\title{
Abrigo e abrigados: construções e desconstruções de um estigma
}

\section{Shelter and sheltered: construction and deconstruction of the one stigma}

\section{Lygia Santa Maria Ayres*}

Pesquisadora e coordenadora do Programa PIVETES do Serviço de Psicologia Aplicada da Universidade Federal Fluminense - UFF, Niterói, RJ, Brasil

\section{Ana Paula Cardoso Coutinho**}

Mestranda do Programa de Pós-Graduação em Psicologia da Universidade Federal Fluminense - UFF, Niterói, RJ, Brasil

\section{Daniele Amaral de Sá***}

Mestranda do Programa de Pós-Graduação em Psicologia Institucional da Universidade Federal do Espírito Santo, Vitória, ES, Brasil

\section{Thainá Albernaz****}

Graduada pelo curso de Psicologia da Universidade Federal Fluminense - UFF, Niterói, RJ , Brasil

\begin{abstract}
RESUMO
Partindo de uma pesquisa bibliográfica acerca das produções acadêmicas referentes às temáticas abrigamento, convivência e destituição do poder familiar, entre os anos de 2000 a 2008, constatamos que alguns artigos atribuíam às crianças e aos adolescentes abrigados uma identidade particular, segundo certas concepções psicológicas que os aprisionam em determinadas formas de ser. Esse artigo coloca em análise a construção de estigmas institucionais, dentre eles, déficits nas crianças e jovens abrigados: problemas de atenção, dificuldade de aprendizagem, prejuízos em relação a mecanismos de defesa, excesso de agressividade, embaraços nas relações afetivas, dificuldade de expressão, carência de afetos. A análise do discurso foi a opção escolhida por nos possibilitar compreender todo um leque de relações que atravessam as falas dos especialistas e que participam da produção, reprodução, manutenção ou transformação das práticas sociais e das relações de saber-poder com as suas implicações ético-políticas.

Palavras-chaves: Estigma, Abrigos, Abrigados, Convivência familiar, Produção de subjetividade.
\end{abstract}

\section{ABSTRACT}

Starting from a bibliographic research on the academic productions regarding the themes sheltering, living with family and the dismissal of the family values, we verified that some articles attributed to sheltered children and teenagers a particular identity to sheltered children e and teenagers, 
according to some psychological concepts which imprison them in certain ways of being. This article places in analysis the construction of the stigma of institutions, among them, the shelters and the sheltered. The analysis of the discourse was the option chosen given that it allowed us to comprehend all of the innumerous relations that go through the speech of specialists and that participate of the production, reproduction, maintenance, and transformation of social practices and the relations of the knowing-power with the ethic-political implications.

Keywords: Stigma, Shelter, Sheltered, Living with family, Production of subjectivity.

Este trabalho traduz algumas reflexões produzidas pela pesquisa "Cenários dos abrigos no Brasil: uma leitura a partir de produções acadêmicas", do Programa de Intervenção Voltado às Engrenagens e Territórios de Exclusão Social (PIVETES), realizado pelo Departamento de Psicologia, Laboratório de Subjetividade e Política (LASP) e Serviço de Psicologia Aplicada (SPA) da Universidade Federal Fluminense (UFF).

Esta pesquisa teve início em 2007 e objetivou cartografar (GUATTARI, 1996), as diferentes subjetividades que atravessam as produções acadêmicas sobre as temáticas abrigamento, convivência e destituição do poder familiar. Esta pesquisa se caracteriza como bibliográfica, não envolvendo intervenções em campo, entrevistas, ou contato presencial com o estabelecimento abrigo.

Nosso intuito principal era investigar o que estava sendo produzido sobre o abrigo para crianças e adolescentes. Para tanto, realizou-se um levantamento e análise de artigos, textos, dissertações e teses referentes a essa temática, datados a partir do ano 2000. Esta data é tomada como ponto de partida por corresponder a dez anos da promulgação do Estatuto da Criança e do Adolescente (ECA) e, assim, uma esperada consolidação de seus princípios na sociedade. Coletouse, sobre o tema abrigamento, ao todo: 13 livros, 31 artigos e 28 trabalhos acadêmicos que se distribuem entre teses, dissertações e monografias. Foram consultados trabalhos bibliográficos nos quais a forma abrigo para crianças e adolescentes fosse discutida mesmo que de modo indireto, não se limitando a uma dada área de conhecimento, pois o interesse se dava em perceber como o abrigo e as questões que circundam o tema eram tratados pelos autores. Neste sentido, os trabalhos consultados abrangiam desde pesquisas sobre experiências profissionais, intervenções psicológicas, médicas à pesquisas quantitativas, experimentais, bibliográficas, entre outros. Todos os trabalhos que perpassassem o tema abrigo alcançava o interesse desta pesquisa.

Com o ECA ocorreu uma mudança no sistema de internação de crianças e adolescentes para constituir o atual sistema de abrigamento. Antes o que havia era uma política de assistência 
pautada em grandes complexos de internação. Esses estabelecimentos tinham como característica central ser uma instituição total, ou seja, a escolarização, os atendimentos de saúde e - lazer eram realizados dentro do próprio complexo, ocupados freqüentemente por centenas de crianças.

À época eram internadas crianças e adolescentes que pudessem estar em situação irregular, entendendo este referencial como uma ocasião de abandono, uma circunstância de infração de normas ou mesmo de pobreza, qualquer situação que fugisse aos padrões deveria ser corrigida e controlada, assim, a criança, ao invés de ser assistida, acabava por ser "punida", ficando até a maioridade dentro do estabelecimento.

Já dentro da lógica da proteção integral instaurada com o Estatuto, a criança e o adolescente são vistos como sujeitos de direitos e, sendo um deles a convivência familiar e comunitária, o sistema de abrigamento busca promover articulações com a rede de assistência, objetivando a reintegração familiar ou, quando isto não é possível, a colocação em família substituta. O acolhimento deverá ser feito em pequenos grupos, misturando meninas e meninos de modo a assemelhar-se às características de uma casa.

Tomamos por base a produção escrita levantada como corpo de nossa pesquisa, dentre teses, dissertações, monografias e demais trabalhos acadêmicos, todos datados entre os anos de 2000 e 2008. Os discursos e os conteúdos veiculados pelos especialistas (autores e co-autores) foram trabalhados segundo a análise do discurso, tomando-se como principais norteadores os trabalhos de Foucault (2000 e 2004) e algumas contribuições de Rocha-Coutinho (1994, 1998) e Orlandi (2002).

A análise do discurso foi a opção escolhida por nos possibilitar compreender todo um leque de relações que atravessam as falas dos especialistas e que participam da produção, reprodução, manutenção ou transformação das práticas sociais e das relações de saber-poder com as suas implicações ético-políticas.

Chamamos aqui de especialistas àqueles que se colocam na posição de detentores de uma verdade agindo em nome de um saber neutro e científico. Foucault explicita bem esta questão quando indaga "que saber vocês querem desconsiderar quando dizem é uma ciência?" (1979, p.172).

Ao longo das leituras e discussões sobre os textos coletados, retiramos, destes, categorias de análise. Uma das categorias que se mostrou proeminente durante as análises foi por nós denominada de Estigma Institucional.

Essa pesquisa não teve a pretensão de apresentar modelos, e sim dar visibilidade, realizar outras leituras acerca dos atravessamentos que vêm constituindo a instituição abrigo e a subjetividade abrigados, na medida em que percorremos em nosso trajeto, não a estrada do 
conhecimento movido pela busca de verdades contidas em questões fechadas, mas a via da interrogação, expressa na abertura ao debate e ao questionamento.

Nesse sentido, os analisadores aqui apresentados não têm a função de desqualificar profissionais ou mesmo correntes psicológicas, mas apenas apontar como diferentes concepções teóricas constroem práticas sociais diferenciadas.

\section{O discurso como prática social, como construção de subjetividades.}

Muitos dos artigos levantados referiam-se ao abrigo como um espaço, local geográfico com a finalidade de possibilitar à criança ou ao adolescente seu pleno desenvolvimento enquanto ser em formação. Assumem como modelo, ou seja, como ponto de referência, a família dita normal e burguesa, constituída pelas figuras paterna e materna. Consideram e afirmam a ausência desses modelos/papéis como condições favoráveis ao fracasso na afirmação como sujeitos saudáveis. A partir dos trabalhos coletados destacamos alguns em que a observação acima pode ser vista:

Quanto ao desempenho escolar, foi encontrada diferença entre o grupo institucionalizado e o grupo que mora com a família apenas entre as crianças, sendo que o grupo institucionalizado apresentou médias mais baixas. Este resultado confirma a idéia inicial de que a família desempenha um papel importante no desempenho escolar das crianças. (DELL'AGLIO; HUTZ, 2004, p.355)

Pode-se considerar que, mesmo que a instituição ofereça o atendimento de necessidades básicas ao desenvolvimento de crianças e adolescentes, ela não oferece condições para um atendimento individualizado, com estabelecimento de laços afetivos, que podem ser alcançados mais facilmente num ambiente familiar. (DELL'AGLIO; HUTZ, 2004, p.356).

Nesse sentido, o simples fato de estar abrigado já comprometeria o pleno desenvolvimento do indivíduo.

De qualquer forma, mesmo em instituições de alta qualidade, a inteligência e autonomia de crianças deste contexto são marcadamente menores do que aquelas que foram cuidadas em suas casas. (SIQUEIRA; DELL'AGLIO, 2006, p.73)

Ao falarmos da criança abrigada, encontramos muitas semelhanças com as características das crianças adotivas. (...) Observamos que, desde o início de seu desenvolvimento, há perturbações sérias nas relações de objeto, resultando em muita sensibilidade frente a situações de separação e um medo exacerbado em serem 
abandonadas. Essas crianças devem ter ficado expostas a intensas cargas de ansiedade provenientes de situações como a separação da mãe, que deixa marcas em seu desenvolvimento. O medo de novas perdas das pessoas de quem dependem ou a quem estão ligadas parece acompanhar a criança como uma cicatriz dolorosa e pronta para se abrir a qualquer momento. (ROTONDARO, 2002) ${ }^{1}$

O sentimento de abandono causado pela institucionalização pode gerar dificuldades nas futuras relações constituídas pelo indivíduo. O abandono pode se expressar na carência afetiva, fazendo o indivíduo se apegar com facilidade às pessoas que lhe dão atenção, ou pode faz-lo evitar as relações pessoais por temer ser abandonado novamente. (RICARDO; LAVORATTI, 2007, p. 254)

Nessa mesma lógica, os especialistas atribuíam às crianças e aos adolescentes abrigados características ditas psicológicas, tais como, depressão, insegurança, inferioridade intelectual, tornando-os um grupo que poderia ser identificado por esses comportamentos.

A criança institucionalizada geralmente tem uma visão negativa de si mesmo, restringindo, desta forma, as relações de aceitação social que são reforçadas pelo estigma institucional. (DELL'AGLIO; HUTZ 2004, p. 356)

A dificuldade das crianças em estabelecer vínculos afetivos pode estar relacionada: às suas frustrações em sua trajetória de vida, à rotatividade de funcionários e à capacitação dos funcionários em lidar com essas crianças. (MONTES, 2006, p. $61)$.

A identificação com valores familiares leva as crianças a resolverem conflitos no grupo, utilizando-se de formas agressivas de enfrentamento. Somando-se a isso, a separação das famílias torna a experiência de abrigo mais difícil e dolorosa. Para elas, a família é o centro de seu afeto e de suas preocupações. O processo de análise dos dados possibilitou perceber que a separação causa intenso abalo emocional e muita dificuldade para lidar com a situação. (MONTES, 2006 p. 59).

Diante da desigualdade de poder, o grande perdedor é a sociedade. Os reflexos podem ser notados tanto no presente como no futuro. As vítimas acabam assimilando valores desfigurados de respeito humano. A vulnerabilidade e a fraqueza temporárias da criança, enquanto vítima, podem dar lugar à formação de pessoas que exerçam o papel de agressoras dentro e fora do contexto familiar, mediante mecanismos de introjeção e identificação com o que a 
vitimiza. É a violência dentro da família gerando a violência social. (MONTES, 2006 p. 59).

Tal lógica determinista encontra respaldo na Psicologia Diferencial, tendo como interesse investigar especialmente as diferenças de inteligência, temperamento e personalidade e, por extensão, numa determinada forma de conceber o indivíduo e significar suas relações com seus pares e com o mundo.

Historicamente, esse saber, construído com a finalidade de normatizar, regular comportamentos e vidas, assenta-se sob as bases de uma visão mecanicista e dualista do conhecimento, sustentandose, por vezes, na lógica dicotômica da medicina (saúde/doença, normal/patológico, prevenção/tratamento) concebendo, assim, o indivíduo como somatório de duas entidades distintas que se tangenciam, mas não se atravessam. Castoriadis (1975) pontua que o processo da instituição social do indivíduo é o resultado de duas histórias indissociáveis: uma história da psyque (psicogênese), ao longo da qual esta se altera e se abre ao mundo social-histórico e uma história social, na qual a sociedade lhe imprime um modo de ser (sociogênese), que ela não poderia jamais fazer surgir dela mesma e que fabrica o indivíduo social que emerge como coexistência sempre impossível e sempre realizada, de um mundo privado (Kosmos idios) e de um mundo público (Kosmos Koinos).

Longe dessa vertente teórico-prática, Guattari (1996) nos apresenta uma outra leitura/concepção do indivíduo contemporâneo, por ele denominada de produção de subjetividade, entendida não como sinônimo de individualidade, mas fabricada e modelada no social. Sendo assim, a subjetividade não é algo interno ao sujeito, mas é um modo de existência produzido por forças que não estão nem fora nem dentro dele, mas se interceptam e se conjugam, fazendo emergir certos padrões que, em determinado momento, se tornam hegemônicos, ditando as formas de viver, de se relacionar, de produzir, etc.

A forma de ver o sujeito como um ente possuidor de uma identidade eterna, forjada pelas suas vivências na infância é também uma produção e é preciso estar atento aos seus efeitos na vida de crianças, jovens e famílias. Nesse sentido, a fala do pesquisador que utiliza certos mecanismos científicos para avaliar a criança abrigada não é neutra, mas está envolvida por instâncias que afirmam modelos do que é ser uma criança saudável, do que é uma família estruturada, ou seja, esta fala, apresentada como neutra, também está tomada e atravessada por um ambiente maquínico, sendo, por isso, um discurso político, como todo e qualquer discurso/prática.

Ainda segundo Guattari (1996), estes especialistas e cientistas fazem sempre uma opção reacionária, que pode reforçar a produção da subjetividade dominante ou criar espaços para produção de 
singularidades. Reafirma o autor que o modo indivíduo também é uma produção. A prática em ter o indivíduo como referência, como centro de análise também é uma subjetividade construída e se apresenta, atualmente, como uma perspectiva dominante. Quando os autores pesquisados tomam por análise o jovem abrigado, este é observado a partir de uma concepção sobre o que é ser jovem, no entanto, este funcionamento social é mutante ao longo do tempo, não existindo, universal e estaticamente, uma forma de ser jovem.

Baseando-se na perspectiva de que todo discurso/prática é político e na não existência de uma neutralidade mesmo na pesquisa científica, mas ao contrário, esta também está imersa num campo de forças, é necessário interrogar qual o intuito em procurar o que falta nas crianças abrigadas, o que se quer afirmar e produzir com tal proposta? Neste contexto neoliberal, no qual há uma crescente busca pelo aperfeiçoamento do sujeito, visando um nível de excelência em diversos aspectos da vida, é preciso estar atento a estes movimentos e no uso das ferramentas científicas. A história nos mostra que a Psicologia Diferencial, baseada em estudos experimentais, também criou saberes afirmados em cima do que falta ao sujeito, dando alicerces individuais para as questões sociais. Procurando as aptidões de cada sujeito, a Psicologia Diferencial tentou, através de um modelo de indivíduo ideal, identificar os seres bem adaptados, com o objetivo de evoluir a espécie humana. Este referencial, emergido por volta do século XIX, encontra, ainda hoje, ressonâncias nos discursos de educadores, psicólogos, médicos, etc que, estimulados pelo modelo econômico neoliberal, ganham força.

A produção da subjetividade abrigado acontece não só quando estes autores escrevem sobre as crianças abrigadas e afirmam verdades sobre elas, mas também é no cotidiano que ela se atualiza. Ora na fala dos técnicos, ora na fala dos pais ou dos educadores, produz-se e impõe-se certo jeito de funcionar à criança abrigada. Quando se afirma a vitimização da criança por estar vivendo longe de sua família, já há um discurso de individualização, despotencialização e uma ligação do desenvolvimento saudável atrelado à família. Assim já se demarca um lugar específico de segregação para esta criança em relação àquelas não abrigadas.

A busca pelo modelo de família burguesa ainda se mostra dominante na sociedade contemporânea e, dentro deste contexto, as relações de afeto não mantidas dentro deste molde são desmerecidas e encaradas como inferiores. Somente pelo fato das crianças saírem de suas casas para serem abrigadas, já se supõe um sofrimento. A possibilidade de se viver dentro de outras dinâmicas familiares que não a família nuclear, assim como a criação de vínculos diferenciados na rede de assistência da qual a criança é usuária, não é o grande enfoque nos artigos coletados. A produção de subjetividade que ratifica apenas um tipo de relação saudável para as crianças é 
acentuada também na prática dos funcionários dos abrigos que, em alguns relatos dos trabalhos levantados, se privam em criar vínculos com as crianças devido à medida de abrigamento ser temporária. Isto demarca novamente o referencial de que um vínculo saudável para o desenvolvimento da criança teria que se dar de forma constante e linear, dentro do seio familiar.

Os traços comuns encontrados nos adolescentes acolhidos nos abrigos municipais são a descontinuidade de vínculos, uma alta reincidência de abrigamentos e rotatividade (...) (J ANCZURA, 2005, p. 15)

Não se ver outras possibilidades de vínculos afetivos saudáveis fora da família também é uma produção de subjetividade, a qual ganha corpo nas práticas cotidianas, fabricando desqualificação dos vínculos não familiares e, por vezes, até impedindo-os, como visto na passagem abaixo:

(...) Algumas vezes [a entidade] reforça a segregação e o segredo. Como, por exemplo, ao não permitir que as crianças abrigadas participassem da festa de aniversário de Lucas, filho adotado por uma funcionária da Casa. Como Lucas havia sido recentemente adotado, seus principais vínculos eram as crianças e funcionárias da entidade. Contudo, as crianças não puderam comparecer, pois segundo a coordenação, as crianças iriam se sentir preteridas por não terem sido adotadas pela funcionária. (CRUZ, 2006, p.34)

Não desconsideramos, na sociedade contemporânea, os males provocados pelo rompimento dos laços familiares para crianças e adolescentes e também não é nosso intuito defender a prática de abrigamento como a melhor alternativa para aqueles que têm seus direitos violados e não podem conviver com a família, mas privilegiamos pensar o que se quer produzir quando se instaura como verdade legitimada cientificamente que a infância e a juventude que passaram pelo programa de abrigamento carregarão uma marca que os torna inadequados e inferiores aos padrões de convívio social.

Vale lembrar que, de acordo com a pesquisa realizada pelo IPEA (2004), foi constatado que a grande maioria de usuários do sistema de abrigamento são famílias pobres e, dentro deste quantitativo, a maior parte é constituída por crianças e jovens negros e pardos, o que desvela uma realidade social construída historicamente, não podendo ser vista por um olhar reducionista e individualizante, que toma como centro de análise das causas do abrigamento a dinâmica de determinadas famílias. 
No entanto, para além desse dado, esta situação indica um fato que tem suas raízes produzidas com a propagação e perpetuação das formas de discriminação e desfiliação, instituídas ao longo do tempo. Tal situação é produto de um projeto de ordem político-institucional, não sendo, portanto, uma questão de ordem cultural, como nos lembra Neder “(...) o padrão autoritário presente na organização política brasileira imprimiu continuidade nesta perda de vínculos familiares e crises de identidade entre as classes populares de origem africana, com migrações campo-cidade, por exemplo, e outras separações forçadas" (1994, p.40).

Partindo da concepção foucaultiana do discurso como prática discursiva, os trabalhos bibliográficos não são por nós considerados como mero material de leitura, isto é, como uma dimensão teórica alheia à prática. Foucault (2000) desvela a relação entre as práticas discursivas e os poderes que as permeiam. Ao percorrer os diversos procedimentos sociais de controle dos discursos, o autor mostra que este não atua como um simples tradutor, que nomeia lutas e relações de poder, já que ele próprio é um poder pelo qual se luta. Assim sendo, acreditamos que, por exemplo, conceitos como "menor", "pivete", "abrigado" ou "delinqüente" não foram criados por acaso, mas revelam por si só um posicionamento político a respeito da criança pobre. Estes enunciados são também práticas, pois produzem e reproduzem efeitos no social. Nesse mesmo sentido, marcas institucionais, como afirmam alguns autores dos textos pesquisados, reforçam a noção de estigma.

Não podemos deixar de considerar que esta produção sobre as diversas marcas institucionais, ou seja, os vestígios que a institucionalização pode deixar na criança ou adolescente, data desde muito antes da emergência dos abrigos, indo para além dos dezoito anos do ECA, por ser historicamente produzida, tendo a psicologia como um dos seus pilares. Psicologia, esta, formada, dentre outros, por teóricos como os do desenvolvimento e da personalidade, destacamos como referência na história da psicologia René Sptiz com seus experimentos em orfanatos que destacavam a necessidade do contato materno e John Bowlby em sua teoria do apego, também destacando a importância da figura materna.

Segundo essas concepções psicológicas às crianças e aos adolescentes abrigados é atribuída uma identidade particular, aprisionando-os em determinadas formas de ser. Este determinismo é apresentado pelos discursos científicos por meio de gráficos, cálculos sobre percentuais de crianças em que se observa o mesmo tipo de comportamento, teorias do desenvolvimento, enfim, diversos instrumentos classificatórios que derivam o mesmo fim, comprovar e prever o destino inevitável das crianças abrigadas.

Goffman, em seu livro Estigma (1982), traz uma interpretação desta forma de tratar os sujeitos a partir de classificações e 
homogeneizações. Este autor diz que o estigma é uma identidade social, ou seja, uma marca instituída de forma a definir previamente os atributos de quem a carrega.

O estigma aponta que tal sujeito é diferente de todos os outros que não possuem a marca, sendo, estes últimos, denominados de "normais". À pessoa que possui um determinado estigma não só é atribuído um tipo especial de características, como também é exigido dela que se manifeste no mundo dentro desta identidade forjada. Goffman (1982) diz que os indivíduos estigmatizados não são vistos como completamente humanos, fazendo parte de uma classe inferior, inacessível aos ditos normais.

Entendemos que esta produção de modelos está dentro de nossas relações cotidianas, sendo tecidas por diversos discursos que ratificam a atribuição de uma identidade ao sujeito, tomando-o por completo. Pensando a adjetivação da infância pobre na história, nos deparamos com conceitos como criança abandonada, carente, delinqüente juvenil, isto sem contar com a associação que passou a ser feita entre criança pobre e menor, desde o Código de Menores de 1927. Produzia-se, assim, já naquela época, um modelo em relação às crianças que fossem institucionalizadas. Isto porque estes estabelecimentos eram voltados para as crianças pobres, em um momento em que pobreza e abandono já eram prontamente transformados em elementos perigosos para a sociedade.

Apesar da conquista da condição de sujeitos de direitos, afirmado com o estabelecimento do ECA, percebe-se que tal garantia atinge de forma diferenciada as crianças e os jovens pobres. Isto porque, grande parte das vezes, a Justiça somente se encarrega deles através do judiciário, ou seja, age apenas no momento de corrigir ou mesmo de puni-los por alguma falha, sem que tenha havido qualquer forma de assistência ou cuidado anterior. Tal abordagem alimenta e é alimentada pela própria "estigmatização" deste grupo de crianças e jovens, além de refletir a insuficiência de políticas públicas na rede social a eles dirigidas.

Retomando o pensamento de Foucault, chegamos ao que ele chama de virtualidade. Esta corresponde a um perigo em potencial que se atribui a um indivíduo ou a um grupo de indivíduos, não por seus atos, mas pelos que poderia vir a cometer. A partir da análise destes modelos produzidos a respeito da infância pobre, entende-se como foram sendo produzidas, durante muito tempo, instituições de cunho corretivo para estas crianças e adolescentes. Isto porque, ainda de acordo com Foucault, toda a rede de poder que não o judiciário, deve executar a mesma função atribuída à justiça, função esta que corresponde não mais a punir as infrações dos indivíduos, mas de corrigir suas virtualidades.

\section{Considerações finais...}


Com o decorrer do tempo, tais conceitos/práticas vão circulando sem críticas ou questionamentos, até serem naturalizados. Mesmo após a implantação do ECA e sua proposição de considerar crianças e adolescentes como sujeitos de direitos e a instauração do programa de abrigos, a institucionalização/abrigamento é tratada, na maior parte das vezes, como um ônus, acarretando sempre prejuízos para aqueles que passam por ela.

Diante disto, ainda que se fale dos abrigos como um reordenamento dos programas de assistência e proteção à infância, isto é, da sua adequação aos preceitos do ECA para que, cada vez mais, corresponda a um local de acolhida e cuidado, onde crianças e jovens possam ser tomados como cidadãos de direitos, a imensa maioria do material levantado em nosso trabalho de pesquisa fala sobre os déficits das crianças abrigadas. Déficit de atenção, dificuldade de aprendizagem, prejuízos em relação a mecanismos de defesa ou, então, excesso de agressividade, assim como embaraços nas relações afetivas, dificuldades de expressão, carência de afetos, dentre outros, são algumas das marcas atribuídas à institucionalização, ou melhor, às crianças e adolescentes institucionalizados. Este tipo de discurso pôde ser claramente notado em diversos textos lidos na pesquisa.

Nesta perspectiva, crianças e adolescentes podem, a partir do ECA, ser vistos como sujeitos de direitos, porém considerados, basicamente, por meio de uma carência, um ônus, um déficit. Ou seja, eles podem ter conquistado o estatuto de sujeito de direitos, mas a produção desta subjetividade onerosa a seu respeito parece perpetuar.

No entanto, há textos que apresentam análises na contramão da perpetuação de um estigma ligado à vida no abrigo, à lógica da menos-valia, do sofrimento, do abandono, por mais que, aparentemente, o pesquisador espere encontrar este tipo de sentimento nas crianças que ali estão. Dentre os materiais levantados destacamos alguns trechos que ilustram o referido:

Em seus discursos (das crianças) não aparecem componentes emocionais, como o ressentimento, a raiva e a culpa pelo fato de viverem em um abrigo. (DIUVANITOMAZONI; VIEIRA, 2004, p. 213)

Este tipo de deslocamento, em que os autores não seguem a lógica determinista do estigma, revela as linhas flexíveis, possibilitadas por pensamentos desprovidos de modelos e ideais, ao considerarem os atravessamentos e produções históricas acerca de instituições, como a família, a infância, os pais, a casa, a criação e todas as outras que permeiam o assunto em pauta. 
Tal pensamento desviante da lógica do estigma favorece e demonstra que o campo de pesquisa não está dado e que os sujeitos abordados não se referem a objetos previsíveis e acabados. Ao trabalharem desta maneira, tais autores estabelecem maior proximidade com os sujeitos em questão, se relacionando com eles sem a mediação de universalismos e ideais. Neste sentido, os trabalhos resultantes desta abordagem e deste contato retratam com maior riqueza o contexto e os atravessamentos sócio-históricos que atuam na dinâmica de abrigamento estudada, livre das estigmatizações sobre a criança ou adolescente em questão e sua família.

\begin{abstract}
Além disso, diversas vezes a família é culpabilizada por não conseguir suprir as necessidades de seus dependentes. Quando as crianças e adolescentes estão em condição de risco, a "culpa" recai sobre a família, sem considerar que esta, muitas vezes, passa dificuldades sócio-econômicas por estar sendo desatendida pelo Estado e pela sociedade. (RICARDO; LAVORATTI, 2007, p. 250/251).

... outras se sentiam aliviadas por terem nova oportunidade de vida; outras, ainda, demonstravam muita resistência por as terem tirado de casa, chegando a afirmar que preferiam morrer a ficar no abrigo,; outras tinham dúvidas...Dúvidas (COELHO, 2007, p.97)
\end{abstract}

Concluímos, então, que, diante de toda lógica determinista e estigmatizante, existem sempre linhas flexíveis, revelando que o campo nunca está acabado e que os atravessamentos sócio-históricopolíticos estão sempre presentes, por mais que se atribua o aspecto da neutralidade ao discurso científico.

\title{
Referências Bibliográficas:
}

CASTORIADIS, C. L'institution imaginaire de la société. Paris: Seuil, 1995.

COELHO, D. C. G. Lobo em pele de cordeiro - Manicômios do Contemporâneo - uma contribuição para se pensar abrigo de crianças. Serra: Formar, 2007.

CRUZ, L. R. (Des) Articulando as políticas públicas no campo da infância: implicações da abrigagem. Santa Cruz do Sul: EDUSC, 2006.

DELL.AGLIO, D. D.; HUTZ, C. S. Depressão e Desempenho Escolar em Crianças e Adolescentes Institucionalizados. Psicologia: reflexão e crítica, Rio Grande do Sul, v.17 n.3, 2004. Disponível em: <http://www.scielo. br/pdf/prc/v17n3/a08v17n3.pdf>. Acesso em: 25 nov. 2009. 
DIUVANI-TOMAZONI, A.; VIEIRA, M. L. Relação de Apego entre Crianças Institucionalizadas que Vivem em Situação de Abrigo. Psicologia em estudo. Maringá, v.9, n.2, 2004. Disponível em: <http://www.scielo.br/scielo. php?pid=S141373722004000200007\&sc ript=sci_arttext\&tIng=en>. Acesso em: 13 fev. 2009.

FOUCAULT, M. Microfísica do poder. Rio de Janeiro: Graal, 1979.

. A Ordem do discurso. São Paulo: edições Loyola, 2000.

$\overline{2} \overline{0} \overline{0}$.

Arqueologia do Saber. Rio de Janeiro: Forense Universitária,

GOFFMAN, E. Estigma: notas Sobre a manipulação da identidade deteriorada. Rio de Janeiro: Zahar, 1982.

GUATTARI, F.; ROLNIK, S. Micropolitica: cartografias do desejo. Petrópolis: Vozes, 1996.

Instituto de Pesquisa Econômica Aplicada - IPEA. Levantamento nacional de abrigos para crianças e adolescentes da rede SAC. 2004, Brasília.

J ANCZURA, R. Abrigos para adolescentes: lugar social de proteção e construção de sujeitos? Textos e contextos, v. 4, n. 4, dez. 2005. Disponível em: $<$ http: //revistaseletronicas. pucrs. br/ojs/index. php/fass/article/view/1000/7 80>. Acesso em: 13 fev. 2009.

MONTES, D. C. O significado da experiência de abrigo e a autoimagem da criança em idade escolar. 2006, Dissertação (Mestrado em Enfermagem) - Faculdade de Enfermagem, Universidade de São Paulo, São Paulo, 98p.

NEDER, G. Ajustando o Foco das lentes: Um novo olhar sobre a Organização das famílias no Brasil. In: KALOUSTIAN, S. (org).

Família Brasileira: a base de tudo. São Paulo: Cortez/UNICEF, 1994.

ORLANDI, E. Análise do discurso: princípios e procedimentos. Campinas: Pontes, 2002.

ROCHA-COUTINHO, M. L. Tecendo por trás dos panos. A mulher brasileira nas relações familiares. Rio de Janeiro: Rocco, 1994.

A análise do discurso em psicologia: algumas questões, problemas e limites. In: SOUZA, L. FREITAS, M. F. RODRIGUES, M. M. P. (orgs). Psicologia: reflexões (im)pertinentes. São Paulo: Casa do Psicólogo, 1998.

RICARDO, R. S. M.; LAVORATTI, C. Um estudo sobre família contemporânea a partir da realidade das adolescentes abrigadas na casa de Santa Luiza de Marillac. Emancipação (UEPG), v.1, n.7, p.243-264, 2007.

ROTONDARO, D. P. Os desafios constantes de uma psicóloga no abrigo. Psicologia: ciência e profissão, v.22, n.3, set. 2002. Disponível

em:

<http://pepsic.bvspsi.org.br/scielo.php?script=sci_arttext\&pid=S141 
498932002000300003\&lng=pt\&nrm=iso>. Acesso em: 13 de fev. 2009.

SIQUEIRA, A. C.; DELL'AGLIO, D. D. O impacto da institucionalização na infância e na adolescência: uma revisão de literatura. Psicologia e sociedade, Porto Alegre, v.18, n.1, p.71-80, 2006.

\section{Endereço para correspondência}

Lygia Santa Maria Ayres

Programa de Intervenção Voltado às Engrenagens e Territórios de Exclusão Social Pivetes UFF, Serviço de Psicologia Aplicada da UFF Campus do Gragoatá - Rua Professor Marcos aldemar Freitas Reis, bloco N, 5o andar, Gragoatá, CEP 24210201, Niterói - RJ , Brasil

Endereço eletrônico: lygia.ayres@gmail.com

Ana Paula Cardoso Coutinho

Programa de Intervenção Voltado às Engrenagens e Territórios de Exclusão Social Pivetes UFF, Serviço de Psicologia Aplicada da UFF Campus do Gragoatá - Rua Professor Marcos aldemar Freitas Reis, bloco N, 5ㅇaㅁ andar, Gragoatá, CEP 24210201, Niterói - RJ, Brasil

Endereço eletrônico: apccoutinho@yahoo.com.br

Daniele Amaral de Sá

Programa de Intervenção Voltado às Engrenagens e Territórios de Exclusão Social Pivetes UFF, Serviço de Psicologia Aplicada da UFF, Campus do Gragoatá - Rua Professor Marcos Aldemar Freitas Reis, bloco N, 5o andar, Gragoatá, CEP 24210201, Niterói - RJ , Brasil

Endereço eletrônico: daniele_as@hotmail.com

Thainá Albernaz

Programa de Intervenção Voltado às Engrenagens e Territórios de Exclusão Social Pivetes UFF, Serviço de Psicologia Aplicada da UFF Campus do Gragoatá - Rua Professor Marcos aldemar Freitas Reis, bloco N, 5o andar, Gragoatá, CEP 24210201, Niterói - RJ, Brasil

Endereço eletrônico: thainaalbernaz@hotmail.com

Recebido em: 06/05/2009

Aceito para publicação em: 07/12/2009

Acompanhamento do processo editorial: Anna Paula Uziel

\footnotetext{
Notas

* Psicóloga, doutora em Psicologia Social.

** Graduada em psicologia pela UFF, bolsista de Iniciação Científica pela FAPERJ à época da pesquisa.

*** Graduada em psicologia pela UFF, bolsista de Iniciação Científica PIBIC à época da pesquisa.

**** Bolsista de Iniciação Científica pela FAPERJ à época da pesquisa.

${ }^{1}$ Disponível em: <http:

//pepsic.bvspsi.org.br/scielo. php?script $=$ sci_arttext\&pid $=S 14149893200200030000$

$3 \& \mid \mathrm{ng}=$ pt\&nrm $=$ iso\&tlng $=$ PT $>$. Acesso em: $\overline{25}$ nov. 2009
} 